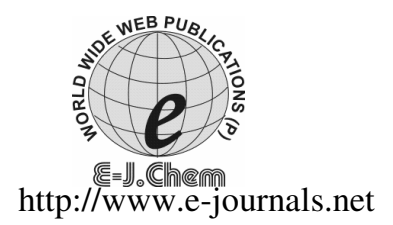

ISSN: 0973-4945; CODEN ECJHAO

E-Journal of Chemistry

$2011,8(2), 767-781$

\title{
Quantitative Determination and Validation of Metformin Hydrochloride in Pharmaceutical Using Quantitative Nuclear Magnetic Resonance Spectroscopy
}

\author{
H.H. GADAPE and K.S. PARIKH* \\ Department of Chemistry, Sheth M.N. Science College \\ Rajmahal Road, Patan-384265, North Gujarat, India \\ drksparikh@gmail.com
}

Received 26 June 2010; Accepted 2 September 2010

\begin{abstract}
Rapid, specific and accurate proton nuclear magnetic resonance spectroscopy ( ${ }^{1} \mathrm{H}$ NMR) method was developed to determine metformin hydrochloride antidiabetic drug in pharmaceutical tablet formulation. The method was based on quantitative NMR spectroscopy (qNMR) using maleic acid as an internal standard and deuterium oxide $\left(\mathrm{D}_{2} \mathrm{O}\right)$ as a diluent. For the quantification of the drug, the ${ }^{1} \mathrm{H}$ NMR signals at $2.91 \mathrm{ppm}$ and $6.25 \mathrm{ppm}$ corresponding to the analyte proton of metformin hydrochloride and maleic acid internal reference standard (IS) respectively were used. The method was validated for the parameters of specificity and selectivity, precision and intermediate precision, linearity, range, limit of detection (LOD) and limit of quantification (LOQ), accuracy, solution stability and robustness. The linearity of the calibration curve for analyte in the desired concentration range was good $\left(\mathrm{R}^{2}=0.9993\right)$. The method was accurate and precise with good recoveries. Range study was also performed up to saturation level $(152.67 \mathrm{mg} / 0.60 \mathrm{~mL})$ in $\mathrm{D}_{2} \mathrm{O}$. The advantage of the method is that no reference standard of analyte drug is required for quantification. The method is nondestructive and can be applied for quantification of metformin hydrochloride in commercial formulation products.
\end{abstract}

Keywords: Metformin hydrochloride, Quantitative NMR spectroscopy, Validation, ${ }^{1} \mathrm{H}$ NMR, Antidiabetic.

\section{Introduction}

Nuclear magnetic resonance (NMR) spectroscopy is a quantitative spectroscopic tool because the intensity of a resonance line is directly proportionate to the number of resonant nuclei. This fact enables accurate and precise determinations of the amount of substance needed. NMR has been used for quantitative determination of pharmaceutical compounds in 
different matrices. The high selectivity under appropriate acquisition conditions and the possibility of performing quantitative analysis without analyte standards are the most attractive features of this technique. Quantitative determination is normally obtained from the ratio between the integration of a specific signal of the analyte and the internal reference standard (IS).

Quantitative measurement was first described in 1963 by jungnickel and forbes ${ }^{1}$ and hollis ${ }^{2}$. Despite limited accuracy, quantitative ${ }^{1} \mathrm{H}$ NMR find application in various fields of science $^{3-13}$. The lack of absorbing chromophores for UV-visible detection and the need for the special chromatographic detectors as well as the difficulties in establishing highly efficient solid or liquid phase extraction procedures have made NMR most suitable for biological sample analysis of many drugs ${ }^{14-17}$.

Metformin hydrochloride is an antidiabetic drug from the biguanide class of oral hypoglycemic agent that has been widely used as a first line treatment of type II diabetes ${ }^{18-20}$, particularly in overweight people, when diet and exercise have failed to control blood sugar levels. It is also effective in individuals at increased risk of developing type II diabetes, having been shown in the diabetes prevention program to reduce ${ }^{21}$ the development of diabetes by $31 \%$. The FDA approved it in December 1994.

Several analytical methods have been reported for the determination of metformin hydrochloride individually or in combination of other antidiabetics in bulk drug form, pharmaceutical formulations and biological fluids. These mainly include chromatographic techniques in association with HPLC ${ }^{22-27}$, capillary electrophoresis $(C E)^{28}$, LC-MS-MS $^{29-30}$, NIR spectroscopy ${ }^{31}$, volumetric analysis with visual endpoint detection ${ }^{32}$ and electro analytical methods ${ }^{33-34}$ etc. Each method enables determination of metformin at different concentration levels and as per its intended application purpose.

Metformin hydrochloride ${ }^{35-36}$ is a pharmacopoeial product. Though the method for quantification of drug is already available in pharmacopoeias but it is titrimetric and requires more authentic, accurate and simple method for its intended purpose. Also as per literature search, there are many analytical methods available for the quantification of drug but almost all the methods are based on lengthy chromatographic techniques. To the best of our knowledge, no official method has been reported by qNMR. Hence the present study has been undertaken. The aim of this work is to develop advantageous and competitive selective NMR method for the determination of the drug in formulation as well as in API samples that complies well with the validation requirements in the pharmaceutical industry.

\section{Experimental}

High purity analytical grade substances were used throughout. Authentic sample of metformin hydrochloride was obtained from local pharmaceutical company and used as a standard as such. maleic acid $(99.90 \%)$, deuterium oxide $\left(\mathrm{D}_{2} \mathrm{O}\right)(99.99 \%)$ and deuterated dimethylsulfoxide (DMSO-d6) $(99.99 \%)$ were purchased from Merck. Glycomet- uncoated tablets containing $500 \mathrm{mg}$ metformin hydrochloride were purchased from the local market (Manufactured by USV Ltd., India).

\section{Instrumentation}

NMR: Bruker AV300 FT-NMR spectrometer operating at a frequency $300.13 \mathrm{MHz}$ (7.1 Tesla) for protons, equipped with a $5 \mathrm{~mm}{ }^{1} \mathrm{H}-{ }^{13} \mathrm{C}$ dual probehead and $5 \mathrm{~mm}$ multinuclear broad band observe (BBO) probehead. 


\section{Preparation of standard and test solutions}

Stock solution of maleic acid IS (10.00 mg $/ 0.6 \mathrm{~mL})$

Accurately weighed $333.335 \mathrm{mg}$ of maleic acid and transferred into $20 \mathrm{~mL}$ volumetric flask. About $10 \mathrm{~mL}$ of $\mathrm{D}_{2} \mathrm{O}$ was added and made up to the mark with same diluent and mixed well.

\section{Standard preparation}

Accurately weighed $10 \mathrm{mg}$ of metformin hydrochloride drug standard and transferred to stoppered tube and $0.6 \mathrm{~mL}$ of stock solution of maleic acid IS was added. Solution was thoroughly mixed till complete dissolution.

\section{Metformin hydrochloride standard preparation for specificity}

$10.30 \mathrm{mg}$ metformin hydrochloride standard was weighed accurately and transferred to stoppered tube and $0.6 \mathrm{~mL}$ of $\mathrm{D}_{2} \mathrm{O}$ was added. Solution was thoroughly mixed till complete dissolution.

\section{Maleic acid (IS) preparation for specificity}

$0.6 \mathrm{~mL}$ of stock solution of maleic acid IS was used directly.

\section{Placebo solution preparation for specificity}

Accurately weighed $13.50 \mathrm{mg}$ of placebo and transferred (mixture of excipients without drug) to stoppered tube and $0.6 \mathrm{~mL}$ of $\mathrm{D}_{2} \mathrm{O}$ was added. Solution was thoroughly mixed till complete dissolution and supernatant was taken for analysis.

\section{Standard preparation for robustness study (IS variation-10.0 $\pm 2.0 \mathrm{mg}$ )}

Accurately weighed and transferred $10.20 \mathrm{mg}$ and $11.30 \mathrm{mg}$ of metformin $\mathrm{HCl}$ drug standard into two different stoppered tube and $8.10 \mathrm{mg}$ and $12.00 \mathrm{mg}$ of maleic acid IS was added to both stoppered tube respectively. Then $0.6 \mathrm{~mL}$ of $\mathrm{D}_{2} \mathrm{O}$ was added. Solution was thoroughly mixed till complete dissolution.

\section{Sample preparation (Tablets)}

Ten tablets of Glycomet were weighed, crushed and thoroughly ground into fine powder. Portion equivalent to $10 \mathrm{mg}$ metformin $\mathrm{HCl}$ drug was weighed accurately and transferred to stoppered tube. Then $0.6 \mathrm{~mL}$ of stock solution of maleic acid IS was added. Solution was thoroughly mixed till complete dissolution and supernatant was taken.

Sample preparation for robustness study (IS variation-10.0 $\pm 2.0 \mathrm{mg}$ )

Accurately weighed $12.60 \mathrm{mg}$ and $12.66 \mathrm{mg}$ ground sample (equivalent to $10.00 \mathrm{mg}$ metformin $\mathrm{HCl}$ drug) and transferred into two different stoppered tube and $8.25 \mathrm{mg} \& 12.00$ $\mathrm{mg}$ of maleic acid IS was added to stoppered tube respectively. Then $0.6 \mathrm{~mL}$ of $\mathrm{D}_{2} \mathrm{O}$ was added. Solution was thoroughly mixed till complete dissolution.

\section{NMR analysis}

${ }^{1} \mathrm{H}$ NMR spectra of authentic drug and tablet samples were measured using $300 \mathrm{MHz}$, Bruker-AV300 spectrometer. Typically, 64 scans were collected for each sample into 32,768 data points using a $30^{\circ}$ pulse length; spectral width $6172.839 \mathrm{~Hz}$; digital resolution 0.188380 $\mathrm{Hz} /$ points; preaquisition delay $6 \mu \mathrm{s}$ and acquisition time $2.654 \mathrm{~s}$. A delay time of $25 \mathrm{~s}$ between pulses was used to ensure fully $\mathrm{T}_{1}$ relaxation of protons. 
The FIDs were apodized with $0.3 \mathrm{~Hz}$ exponential line broadening function before Fourier transformation. Manual two-parameter phase correction was used to obtain high quality absorption line shape followed by baseline correction. This manual mode was also used for the signal integration. Chemical shifts were referenced internally to residual water signal obtained at $\delta=4.70 \mathrm{ppm}$.

\section{Procedure for ${ }^{l} H$ NMR spectroscopy method}

The experiments were performed for the standard preparation in replicate $(n=6)$ and sample preparation in triplicate. The ${ }^{1} \mathrm{H}$ NMR under the experimental conditions were recorded and given as per NMR analysis. Integrated analyte ${ }^{1} \mathrm{H}$ signal (singlet) was obtained at $2.91 \mathrm{ppm}$ with respect to ${ }^{1} \mathrm{H}$ signal (singlet) of maleic acid IS at $6.25 \mathrm{ppm}$.

\section{Calculations $^{37}$}

The amount $\mathrm{Wx}$ and assay Px of drug was calculated using the following equations:

$$
\begin{aligned}
W_{x} & =\frac{I_{x}}{I_{S t d}} \frac{N_{S t d}}{N_{x}} \frac{M_{x}}{M_{S t d}} m_{\text {Std }} \\
P_{x} & =\frac{I_{x}}{I_{S t d}} \frac{N_{S t d}}{N_{x}} \frac{M_{x}}{M_{S t d}} \frac{m_{S t d}}{m} P_{S t d}
\end{aligned}
$$

Where, $\mathrm{W}_{\mathrm{x}}=$ Weight of the metformin $\mathrm{HCl}$ drug (in $\mathrm{mg}$ ), $\mathrm{P}_{\mathrm{x}}=$ Assay of the metformin $\mathrm{HCl}\left(\right.$ in $\% \mathrm{w} / \mathrm{w}$ ) on as such basis, $\mathrm{I}_{\mathrm{x}}=$ Mean integral value of the analyte ${ }^{1} \mathrm{H}$ signal obtained at $2.91 \mathrm{ppm}, \mathrm{I}_{\text {std }}=$ Integral value of the ${ }^{1} \mathrm{H}$ signal of maleic acid IS obtained at $6.25 \mathrm{ppm}$, $\mathrm{N}_{\mathrm{std}}=$ Number of protons for the maleic acid IS (2.0), $\mathrm{N}_{\mathrm{x}}=$ Number of protons for the analyte ${ }^{1} \mathrm{H}$ in drug (6.0), $\mathrm{M}_{\mathrm{x}}=$ Molar mass of the metformin $\mathrm{HCl}$ drug $(165.60 \mathrm{~g} / \mathrm{mole}), \mathrm{M}_{\text {std }}$ $=$ Molar mass of the maleic acid IS $(116.07 \mathrm{~g} / \mathrm{mole}), \mathrm{m}_{\mathrm{std}}=$ Weight of the maleic acid IS (in $\mathrm{mg}$ ), $\mathrm{m}=$ Taken weight of the analyte drug (in $\mathrm{mg}$ ), $\mathrm{P}_{\text {std }}=$ Potency of the maleic acid IS $(99.90 \%)$

\section{Results and Discussion}

\section{NMR experiments for confirmation of structure characterization}

Figure 1 shows the structure of analyte drug and IS with its assignments. ${ }^{1} \mathrm{H}$ NMR in DMSO-d6, ${ }^{1} \mathrm{H}$ NMR, ${ }^{13} \mathrm{C}$ NMR and DEPT experiments in $\mathrm{D}_{2} \mathrm{O}$ were performed for confirmation of structure characterization of metformin $\mathrm{HCl}$ drug. There are many $\mathrm{NH}$ protons are present in metformin $\mathrm{HCl}$ molecule and when analysis was performed in $\mathrm{D}_{2} \mathrm{O}$ solvent, all exchangeable protons disappeared. So for correct assignment of all protons ${ }^{1} \mathrm{H}$ NMR was also checked in DMSO-d6 solvent. The ${ }^{1} \mathrm{H}$ NMR of maleic acid IS was also done in $\mathrm{D}_{2} \mathrm{O}$ solvent for confirmation of its structure.

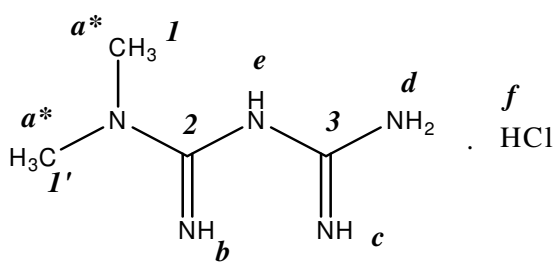

(a)

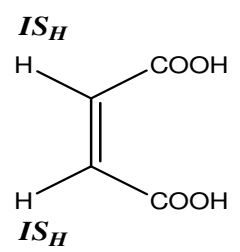

(b)

Figure 1. Structure of (a) metformin $\mathrm{HCl}$ with ${ }^{1} \mathrm{H} \&{ }^{13} \mathrm{C}$ assignment and (b) maleic acid IS with ${ }^{1} \mathrm{H}$ assignment 


\section{Determination of relaxation time $\left(T_{1}\right)$}

For accurate quantification, proper value of relaxation delay is very important. The relaxation delay $(\mathrm{t})$ depends on the longest longitudinal relaxation time $\mathrm{T}_{1}$ of all signals of interest. The $\mathrm{T}_{1}$ relaxation is described by

$$
M_{Z}=M_{0}\left(1-e^{-\left(t / T_{1}\right)}\right)
$$

With $\mathrm{Mz}$ and $\mathrm{M}_{0}$ being the magnetization along the $z$-axis after waiting time $\mathrm{t}$ and at thermal equilibrium, respectively. A delay of five times of relaxation time $\left(\mathrm{T}_{1}\right)$ is normally sufficient between the last RF pulse and the application of the next RF pulse ${ }^{38}$.

The relaxation time $T_{1}$ was determined experimentally by inversion recovery experiment for all the protons of drug and internal reference standard in both the solvents DMSO-d6 \& $\mathrm{D}_{2} \mathrm{O}$ (Table 1). It was found that due to high viscous $\mathrm{D}_{2} \mathrm{O}$ solvent, protons were relaxed slowly and therefore relaxation time was high. That's why $\mathrm{T}_{1}$ value of protons for analyte and internal standard in $\mathrm{D}_{2} \mathrm{O}$ were obtained high compare to in DMSO-d6 solvent. Our method was developed in $\mathrm{D}_{2} \mathrm{O}$ due to very good solubility and therefore we have considered here $T_{1}$ value in $\mathrm{D}_{2} \mathrm{O}$ solvent. The longest relaxation time $4.438 \mathrm{~s}$ was found for the Maleic acid IS and for the proton of interest of drug was $2.035 \mathrm{~s}$. A delay of five $\mathrm{T}_{1}$ 's means $25 \mathrm{~s}$ delay time between pulses was enough to ensure fully $\mathrm{T}_{1}$ relaxation of protons.

Table 1. ${ }^{1} \mathrm{H}$ NMR \& ${ }^{13} \mathrm{C}$ NMR assignments with $\mathrm{T}_{1}$ for metformin $\mathrm{HCl}$ and maleic acid IS

\begin{tabular}{|c|c|c|c|c|c|c|c|}
\hline \multicolumn{8}{|c|}{ Metformin $\mathrm{HCl}$} \\
\hline \multicolumn{4}{|c|}{${ }^{1} \mathrm{H}$ NMR in DMSO-d6 } & \multicolumn{4}{|c|}{${ }^{13} \mathrm{C}$ NMR in $\mathrm{D}_{2} \mathrm{O}$} \\
\hline $\begin{array}{l}\text { Type of } \\
\text { Protons }\end{array}$ & $\begin{array}{c}\text { Assign } \\
\text { as }\end{array}$ & $\begin{array}{l}{ }^{1} \mathrm{H}-\delta \text { ppm } \\
\text { multiplicity }\end{array}$ & $\begin{array}{l}\mathrm{T}_{1} \\
\mathrm{sec}\end{array}$ & $\begin{array}{l}\text { Type of } \\
\text { Carbons }\end{array}$ & $\begin{array}{c}\text { Assign } \\
\text { as }\end{array}$ & $\begin{array}{l}{ }^{13} \mathrm{C}- \\
\delta \mathrm{ppm}\end{array}$ & DEPT \\
\hline $\begin{array}{c}6 \mathrm{H} \\
\left(2 \text { methyl- }-\mathrm{CH}_{3}\right)\end{array}$ & $a$ & $2.911(\mathrm{~s})$ & 0.628 & $\begin{array}{c}2-\mathrm{CH}_{3} \\
\text { (Aliphatic) }\end{array}$ & 1,1 & 37.429 & $2 \mathrm{x}-\mathrm{CH}_{3}$ \\
\hline $\begin{array}{c}4 \mathrm{H} \\
\left(2-\mathrm{NH}, 1-\mathrm{NH}_{2}\right)\end{array}$ & $b, c, d$ & $6.694(s)$ & 0.222 & $\begin{array}{c}1-\mathrm{C} \\
(1-\text {-imine })\end{array}$ & 2 & 158.391 & - \\
\hline $\begin{array}{c}2 \mathrm{H} \\
(1-\mathrm{NH}, 1-\mathrm{HCl})\end{array}$ & $e, f$ & $7.207(\mathrm{~s})$ & 0.205 & $\begin{array}{c}1-\mathrm{C} \\
(1-\text {-imine })\end{array}$ & 3 & 160.061 & - \\
\hline 2H-(ethylene) & $\begin{array}{l}\text { Maleic Ac } \\
\qquad I S_{H} \\
\text { I NMR in } \\
\text { Ietformin }\end{array}$ & $\begin{array}{l}\text { id IS } \\
6.251(\mathrm{~s}) \\
\mathrm{D}_{2} \mathrm{O} \\
\mathrm{HCl}\end{array}$ & 2.128 & & & & \\
\hline $\begin{array}{c}6 \mathrm{H} \\
\left(2 \text { methyl- } \mathrm{CH}_{3}\right)\end{array}$ & $a^{*}$ & $2.914(\mathrm{~s})$ & 2.035 & & & & \\
\hline 2H-(ethylene) & $\begin{array}{c}\text { Maleic Ac } \\
I S_{H}\end{array}$ & $\begin{array}{l}\text { id IS } \\
\quad 6.25(\mathrm{~s}) \\
\end{array}$ & 4.438 & & & & \\
\hline
\end{tabular}

Assignment of ${ }^{1} H$ NMR signals of the drug and IS

Figure 2 shows the ${ }^{1} \mathrm{H}$ NMR spectra for metformin $\mathrm{HCl}$ in DMSO-d6. The sharp singlet was observed at $2.91 \mathrm{ppm}$ due to two equivalent methyl groups assigned as $a$. The 2 protons $(1 \mathrm{H}$ from $-\mathrm{NH} \& 1 \mathrm{H}$ from $\mathrm{HCl}$ ) assigned as $e \& f$, gave combined signal as singlet at $7.20 \mathrm{ppm}$. Remaining 4 protons ( $2 \mathrm{H}$ from $-\mathrm{NH} \& 2 \mathrm{H}$ from $-\mathrm{NH}_{2}$ ) assigned as $b, c \& d$ showed singlet at $6.69 \mathrm{ppm}$. The other signals obtained at $2.49 \mathrm{ppm}$ and $3.30 \mathrm{ppm}$ are due to residual solvent and water of solvent of the DMSO-d6 respectively. 


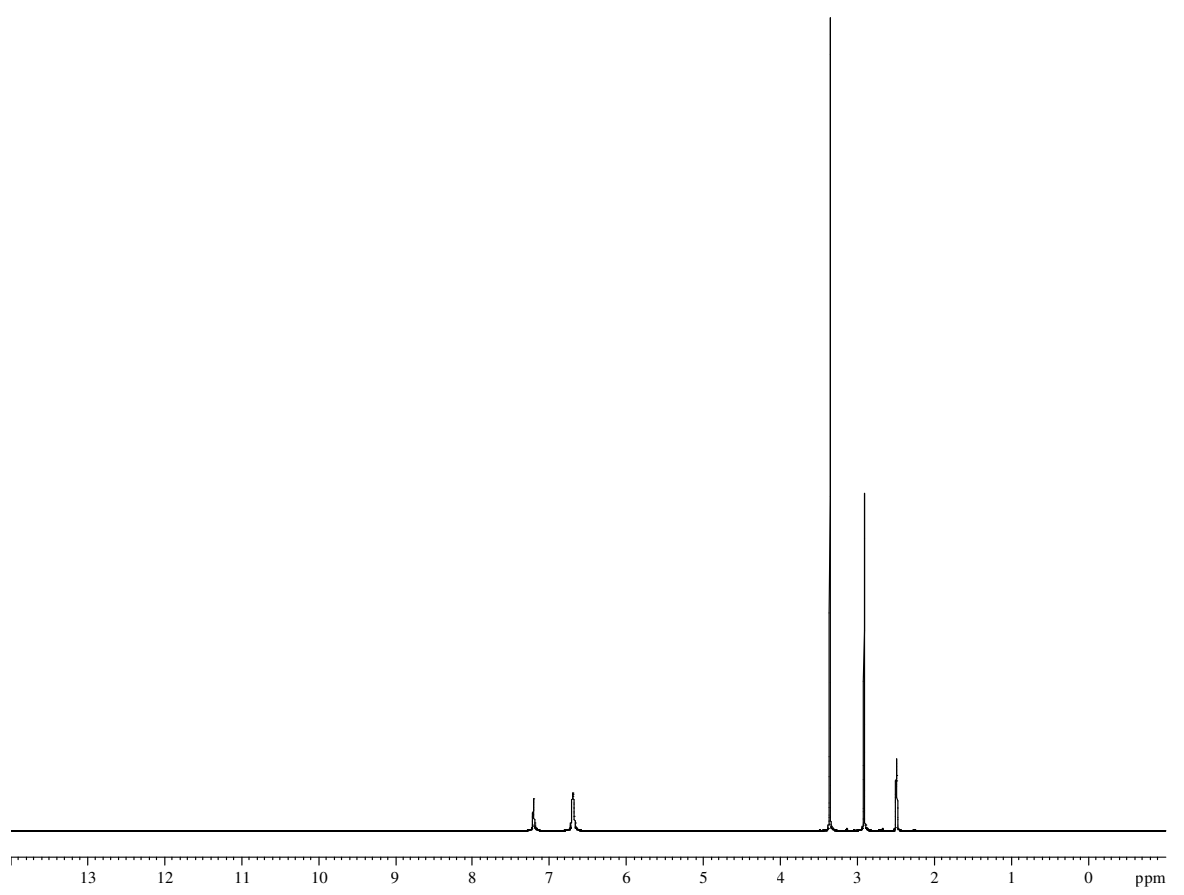

Figure 2. ${ }^{1} \mathrm{H}$ NMR spectrum of metformin $\mathrm{HCl}$ in DMSO-d6

All above proton assignment was also checked in $\mathrm{D}_{2} \mathrm{O}$ solvent. There were observed that all $-\mathrm{NH}$ \& $\mathrm{HCl}$ protons were exchanged in $\mathrm{D}_{2} \mathrm{O}$ by eliminating the signals at $7.20 \& 6.69 \mathrm{ppm}$ (Figure 3 ).

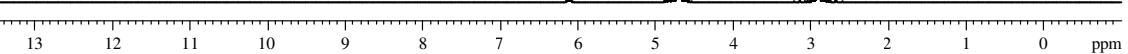

Figure 3. ${ }^{1} \mathrm{H}$ NMR spectrum of metformin $\mathrm{HCl}$ in $\mathrm{D}_{2} \mathrm{O}$ 
The isolated, sharp singlet signal appeared at $2.91 \mathrm{ppm}$ due to two equivalent methyl groups assigned as $a^{*}$ was selected for quantitative determination of the drug. The isolated, sharp singlet signal at $6.25 \mathrm{ppm}$ was due to methylene protons of maleic acid IS and was used as standard signal for quantitative determination (Figure 4).

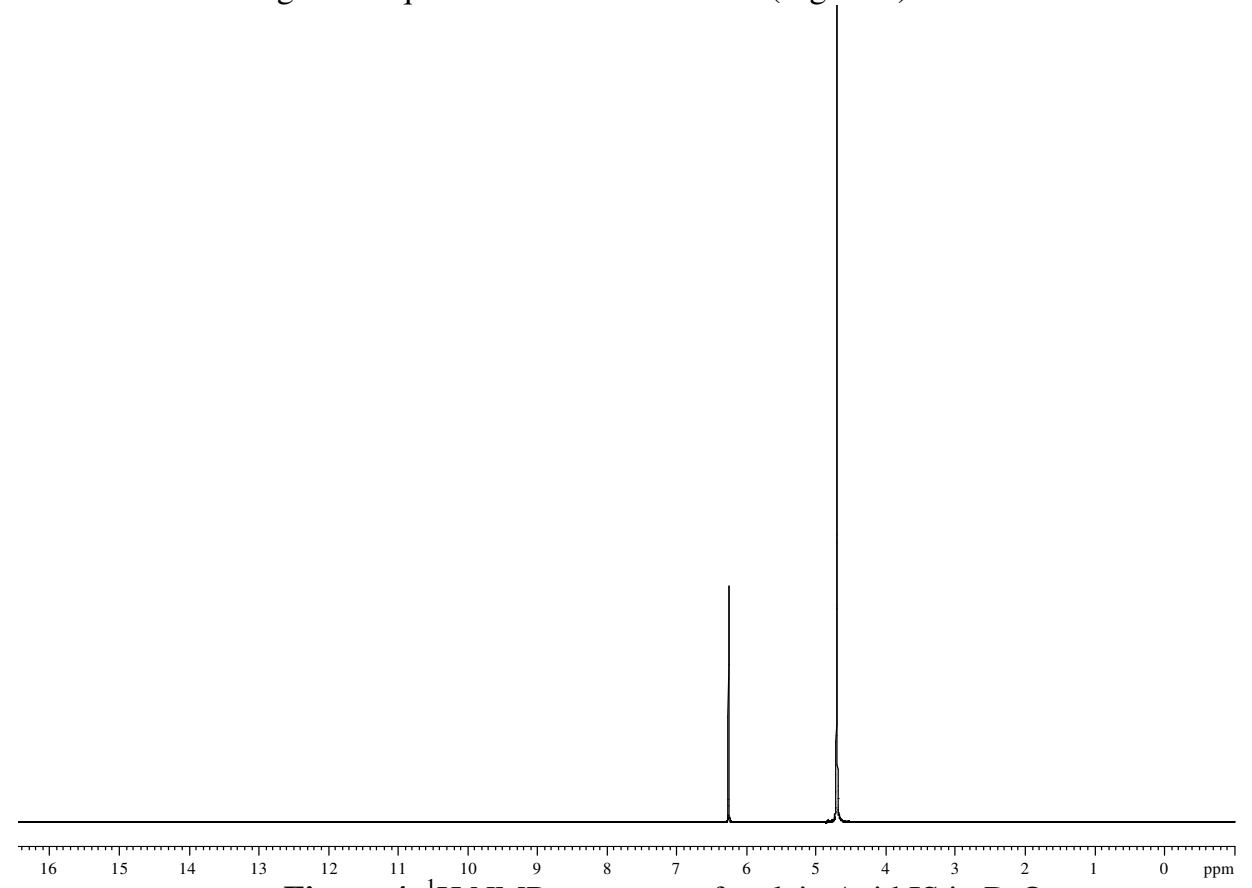

Figure 4. ${ }^{1} \mathrm{H}$ NMR spectrum of maleic Acid IS in $\mathrm{D}_{2} \mathrm{O}$

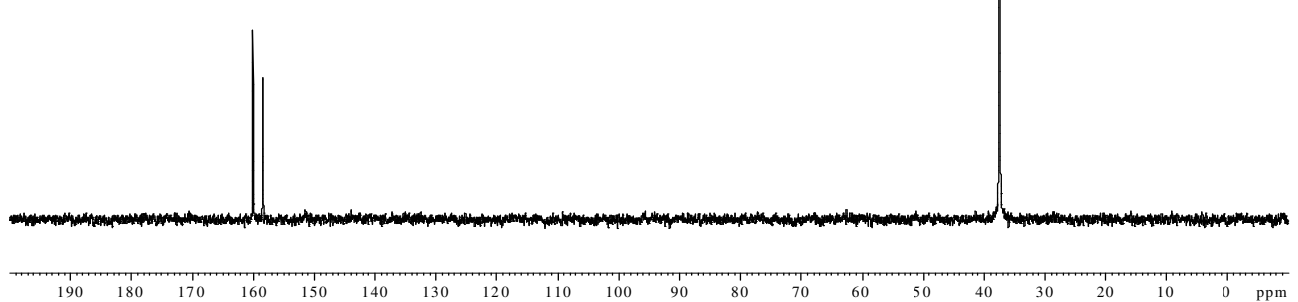

Figure 5. ${ }^{13} \mathrm{C}$ NMR spectrum of metformin $\mathrm{HCl}$ in $\mathrm{D}_{2} \mathrm{O}$ 
The other signal at $4.70 \mathrm{ppm}$ can be attributed to the residual water protons. Additionally, assignment of protons of drug molecule had been confirmed with ${ }^{13} \mathrm{C}$ NMR (Figure 5) and DEPT (Figure 6) experiments in $\mathrm{D}_{2} \mathrm{O}$ solvent. Figure 1 and Table 1 summarize band assignments for all signals.

DEPT135

DEPT90

13C-NMR

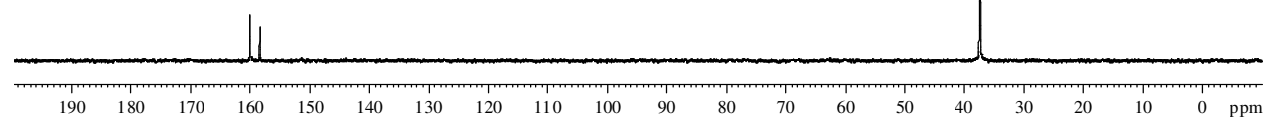

Figure 6. ${ }^{13} \mathrm{C}$ NMR with DEPT experiment of metformin $\mathrm{HCl}$ in $\mathrm{D}_{2} \mathrm{O}$

\section{Quantitative NMR method}

The signal intensity of a known amount of an IS was compared to the area of the peaks originating from the analyte. In the current study, the IS chosen was maleic acid, since it supplies a well-separated signal without any interference from analyte drug signal in the integration region. Of all the common internal standards used in our lab, this was the best choice with respect to both solubility and the chemical shifts of the different protons compared to the drug and other substances in the samples. The singlet of maleic acid chosen for quantification was assigned a value of 2.00 in each NMR spectra.

For metformin hydrochloride, the singlet at $2.91 \mathrm{ppm}$, originating from six protons of the two equivalent methyl groups was used, since this peak appears well separated from other signals. The ${ }^{1} \mathrm{H}$ NMR spectrum of standard and sample preparation in $\mathrm{D}_{2} \mathrm{O}$ shows a well-separated singlet of each analyte proton and the IS (Figure 7).

\section{Validation of method}

The method was validated as per International Conference on Harmonization (ICH) guidelines $^{39}$ for following parameters- system suitability, specificity and selectivity, precision and intermediate precision, linearity, LOD and LOQ, range, accuracy and robustness. 


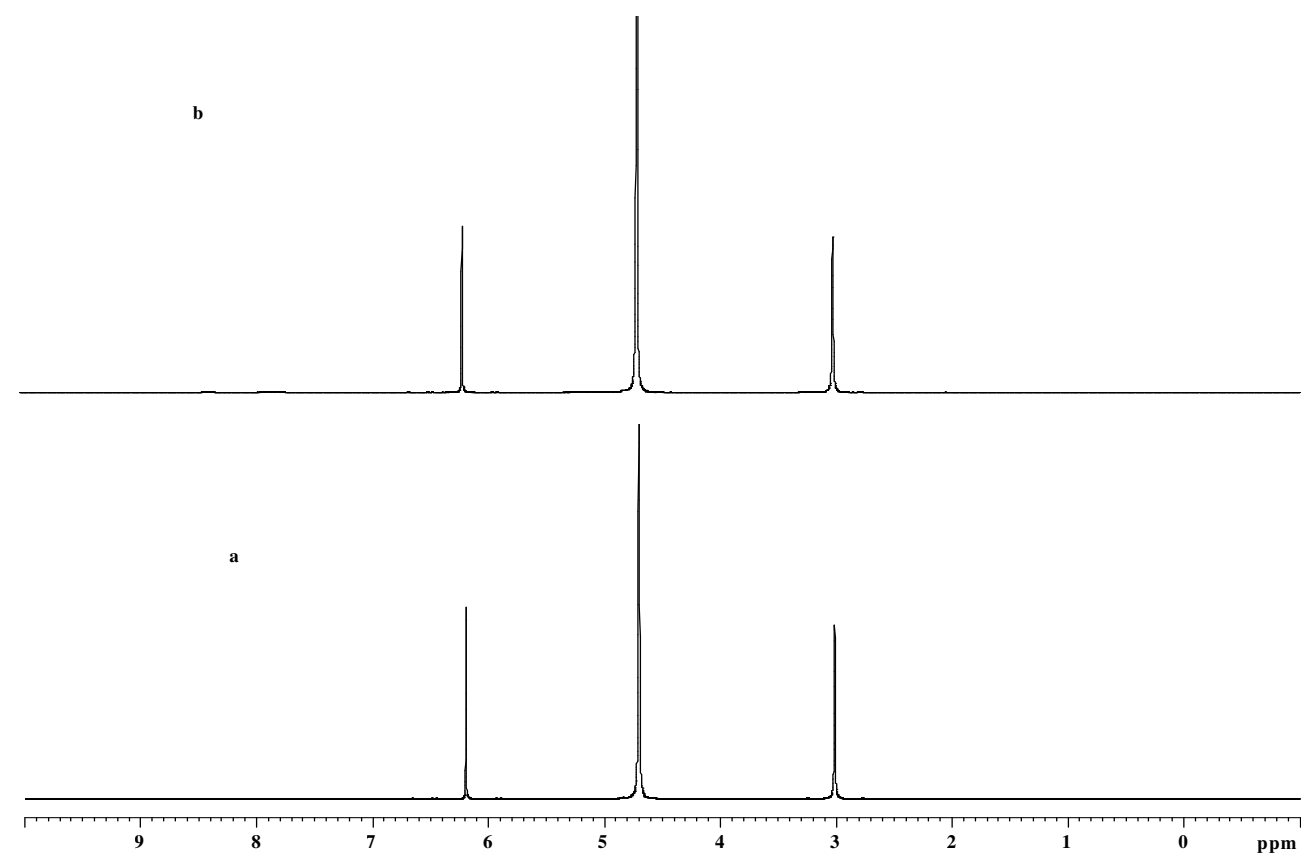

Figure 7. ${ }^{1} \mathrm{H}$ NMR spectrum of (a) Standard preparation and (b) Sample preparation

\section{System suitability}

System suitability - to show that the control measures required have been complied with for a particular analysis on a particular day, a system suitability check is required. Such a check on the performance of the spectrometer and method may be used, for example, to ensure that the expected specificity and sensitivity can be achieved. One of the advantages of the use of NMR as a quantitation method is that the sample itself may provide such system suitability test by, for example, making use of line-width or $\mathrm{S} / \mathrm{N}$ data in the sample spectrum.

Because of the high precision and intrinsic accuracy, system precision for NMR is not required. How ever system precision was performed for every parameter by replicate acquisitions of standard preparation. It was called as system suitability test and checked the compliance of acceptance criteria as mentioned below.

$\%$ Relative standard deviation (RSD) of the integral value of analyte signal should not be more than $2.00^{40}$, Signal to Noise Ratio $(\mathrm{S} / \mathrm{N})$ of the analyte signal should be more than $150^{37,40}$ and difference of the $\delta$ ppm value of analyte signal should not be more than $0.2 \mathrm{ppm}$.

All above three acceptance criteria are defined in-house. Because in quantification, it is already accepted that first two parameters means peak area (integration) and $\mathrm{S} / \mathrm{N}$ ratio of analyte signal are very critical for accurate and precise results. Moreover, another important parameter chemical shift is also included here because the position of analyte peak should be identified properly. A result of the system suitability was meeting the acceptance criteria at each validation study. Means system was precise and suitable for analysis.

\section{Specificity and selectivity}

The selectivity and specificity of proposed method was evaluated through possible interference due to the presence of the excipients in the pharmaceutical formulations. 
Specificity study was performed by analyzing the diluent $\left(\mathrm{D}_{2} \mathrm{O}\right)$, placebo solution preparation, metformin $\mathrm{HCl}$ standard preparation, maleic acid IS preparation and sample (tablet) preparation. It was concluded that there was no interference at the signals obtained at $2.91 \mathrm{ppm}$ and $6.25 \mathrm{ppm}$ for analyte proton \& IS respectively due to diluent \& placebo. Also the signals of the analyte proton and IS were well separated from each other in standard and sample preparations (Figure 8).
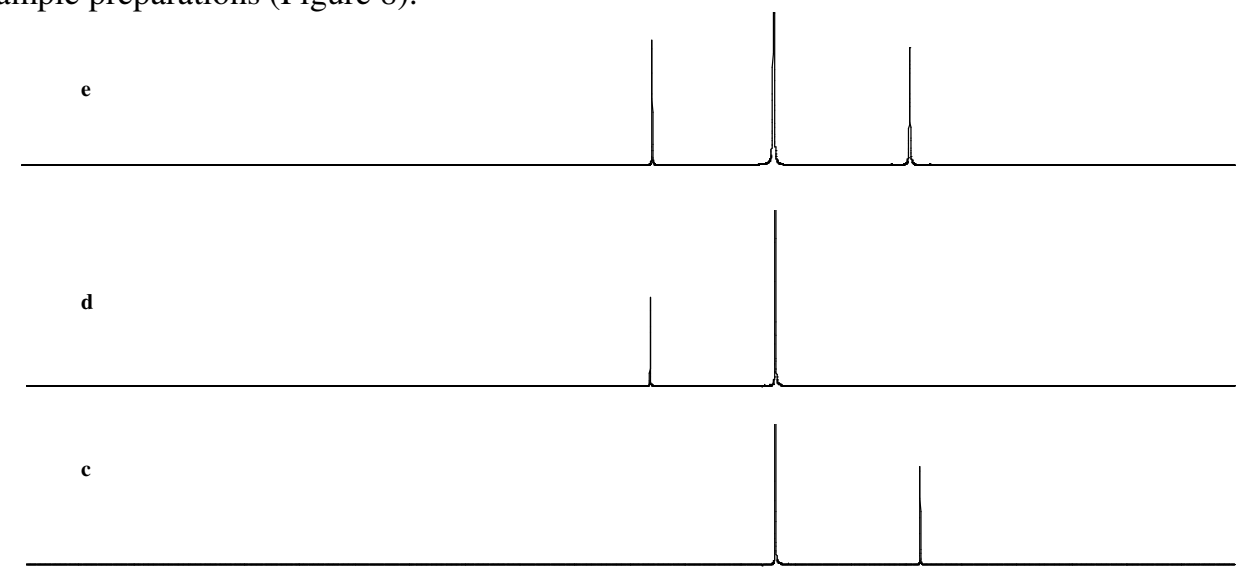

b
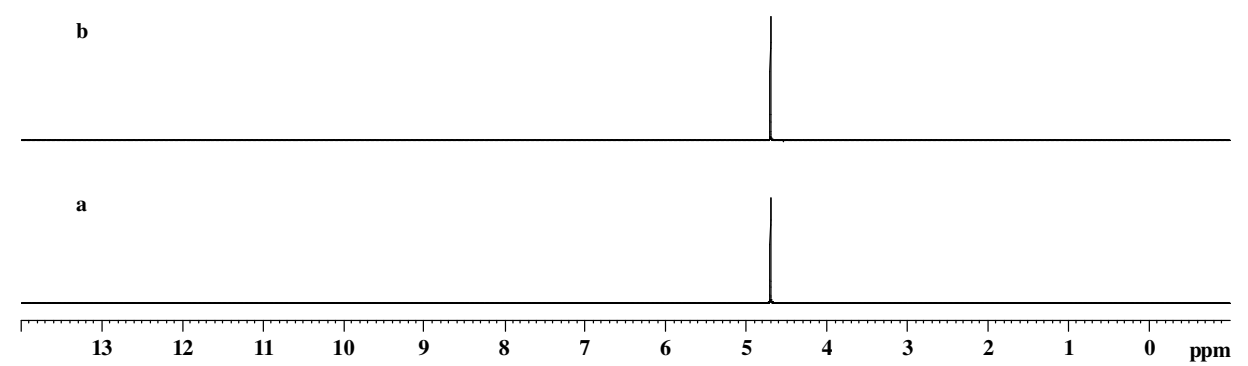

Figure 8. ${ }^{1} \mathrm{H}$ NMR spectra of (a) $\mathrm{D}_{2} \mathrm{O}$ diluent, (b) Placebo, (c) Metformin $\mathrm{HCl}$, (d) Maleic acid IS and (e) Sample preparation

\section{Precision \& intermediate precision}

The precision of an analytical method expresses the closeness of agreement between a series of measurements obtained from multiple sampling of the same homogenous sample. The precision of the integration procedure of qNMR depends on the $\mathrm{S} / \mathrm{N}$ ratio of the signals of interest. $\mathrm{S} / \mathrm{N}$ of at least 150:1 is necessary for every resonance line; which should be integrated, for a precision better than $99 \%$ or an uncertainity of $1 \%{ }^{37}$. Also according to the ICH guidelines the precision will be acquired by six repeated determinations $(n=6)$ and intermediate precision will be evaluated by a different analyst on different day and/or different NMR probe and/or a different NMR spectrometer with a different magnetic field strength.

The precision was assessed by six separate sample preparations. Calculated the content of drug in \%assay for each preparation and statistical results were tabulated (Table 2). S/N ratio for each measurement was calculated and found to be more than 150:1. The biggest factor of influence on the quality of a qNMR analysis is the handling of the NMR data by 
different analysts or operators ${ }^{37}$. Integration of peaks as well as phase and baseline correction is the most subjective parts of the method. Therefore, intermediate precision was determined by performing measurements on three different occasions. Six different sample preparations were prepared and analyzed on $5 \mathrm{~mm}$ multinuclear BBO probehead by different analyst and on different day. The average of six analyses, standard deviation (SD) and RSD values are documented in Table 2. Precision and intermediate precision results did not show any marked differences.

Table 2. Precision and intermediate precision test results

\begin{tabular}{ccccccc}
\hline Study & Precision & & \multicolumn{3}{c}{ Intermediate precision } \\
\hline Preparation & $\begin{array}{c}\text { Taken } \\
\text { drug, mg }\end{array}$ & $\begin{array}{c}\text { *Found } \\
\text { drug mg }\end{array}$ & $\begin{array}{c}\text { \%Assay } \\
\text { (as such) }\end{array}$ & $\begin{array}{c}\text { Taken } \\
\text { drug, mg }\end{array}$ & $\begin{array}{c}\text { *Found } \\
\text { drug, mg }\end{array}$ & $\begin{array}{c}\text { \%Assay } \\
\text { (as such) }\end{array}$ \\
\hline 1 & 10.00 & 10.02 & 100.06 & 10.00 & 10.05 & 100.36 \\
2 & 10.45 & 10.61 & 101.43 & 10.42 & 10.69 & 102.47 \\
3 & 10.42 & 10.66 & 102.17 & 10.69 & 10.86 & 101.53 \\
4 & 10.34 & 10.54 & 101.89 & 10.46 & 10.70 & 102.18 \\
5 & 10.39 & 10.58 & 101.68 & 10.38 & 10.60 & 102.08 \\
6 & 9.96 & 9.99 & 100.21 & 9.92 & 10.00 & 100.70 \\
& & Mean & 101.24 & & Mean & 101.55 \\
& & SD & 0.8925 & & SD & 0.8543 \\
& & \%RSD & 0.88 & & \%SD & 0.84 \\
\hline
\end{tabular}

\section{Linearity}

${ }^{*}$ Average of three determinations.

qNMR as a method itself is linear because the intensity of the response signal is directly proportional to the amount of nuclei contributing to this signal. Linearity was checked by preparing standard solutions at seven different concentration levels ranging from $75 \%$ to $140 \%$, according to the content of analyte in test sample. Linearity curve was drawn for taken drug amount (in $\mathrm{mg}$ ) $v s$. found drug amount (in $\mathrm{mg}$ ). The equation for curve was $\mathrm{y}=1.0096 \mathrm{x}$ +0.0578 . The correlation coefficient was found 0.9993 , indicating good linearity (Figure 9).

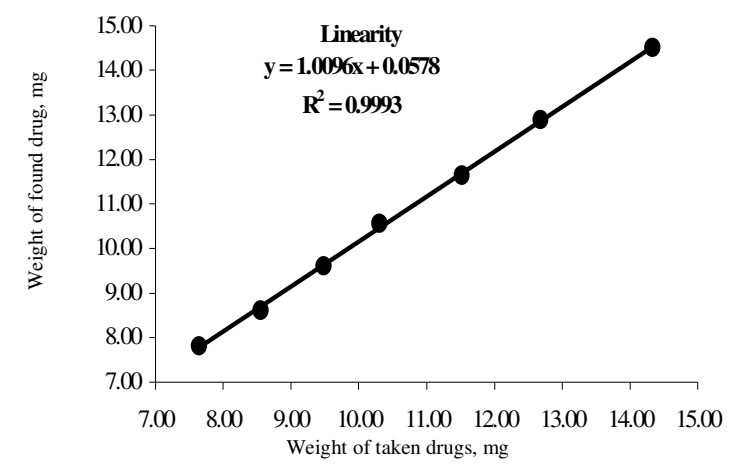

Figure 9. Linearity curve of found drug amount in mg vs. taken drug amount in $\mathrm{mg}$ $\angle O D \& L O Q$

In the case of NMR with lorentzian lines as response signals, the LOD and LOQ have to be calculated by the standard deviation of the response $\sigma$ and the slope $S$ of a calibration curve obtained in Linearity study. The LOD and LOQ were calculated using Eq. (4) and Eq. (5) respectively ${ }^{41}$

$$
\mathrm{LOD}=\frac{3.3 \sigma}{\mathrm{S}}
$$




$$
L O Q=\frac{10 \sigma}{S}
$$

LOD and LOQ were found to be $0.23 \mathrm{mg}$ and $0.68 \mathrm{mg}$ per $0.6 \mathrm{~mL}$ of diluent respectively.

\section{Range}

The range study was determined by preparing solutions of drug up to saturated concentration in solution. Saturated solution was prepared by adding excess drug amount and analyzing supernatant solution for determining the dissolved concentration of drug. Saturation concentration was found $152.67 \mathrm{mg}$ per $0.60 \mathrm{~mL}$ diluent.

\section{Accuracy}

The accuracy of an analytical method expresses the closeness of agreement between an accepted reference value and the value found. The accuracy of an analytical procedure should be established across its range. The ICH documents recommend that accuracy should be assessed using a minimum of nine determinations over a minimum of three concentration levels, covering the specified range (i.e. three concentrations and three replicates of each concentration).

Data from nine determinations over three concentration levels covering the specified range was determined. The accuracy was studied at 80,100 and $120 \%$ levels with respect to the sample by preparing the solutions in triplicate at each level. From the results as per Table 3, it was concluded that method for assay content was accurate between the ranges of 80 to $120 \%$ level. \%RSD at each level was found to be less than 2.00.

Table 3. Accuracy test results

\begin{tabular}{cccc}
\hline Accuracy level & Taken drug, mg & *Found drug, mg & \%Assay (as such) \\
\hline $80 \%$ Set-1 & 8.10 & 8.31 & 102.43 \\
$80 \%$ Set-2 & 8.16 & 8.40 & 102.80 \\
$80 \%$ Set-3 & 8.22 & 8.34 & 101.32 \\
$100 \%$ Set-1 & 10.34 & 10.50 & 101.45 \\
$100 \%$ Set-2 & 10.42 & 10.68 & 102.40 \\
$100 \%$ Set-3 & 10.59 & 10.75 & 101.45 \\
$120 \%$ Set-1 & 11.93 & 12.11 & 101.42 \\
$120 \%$ Set-2 & 12.04 & 12.35 & 102.45 \\
$120 \%$ Set-3 & 12.20 & 12.36 & 101.18 \\
& & Mean & 101.88 \\
& Overall & SD & 0.6270 \\
& & \%RSD & 0.62 \\
\hline
\end{tabular}

*Average of three determinations

\section{Stability of analyte in solution}

Stability of analytes (and standard) over the analysis period - self-evidently the system under test must not change during the test if the results from the test are going to be meaningfully related to the original sample. The solution is said stable, if \% difference in assay is not more than 1.0 when compared to initial value. If solution is not stable at room temperature, same study is repeated at refrigeration temperature $\left(\sim 2-8^{\circ} \mathrm{C}\right)$.

Standard preparation and sample preparation were analyzed at ambient temperature $\left(\sim 25^{\circ} \mathrm{C}\right)$ at $0 \mathrm{~h}$ (Initial), $6 \mathrm{~h}, 12 \mathrm{~h}, 18 \mathrm{~h}$ and $24 \mathrm{~h}$ intervals and calculated \%assay for each interval. Measured \%difference for both preparations at different time intervals with respect to the corresponding initial value and found no major change. Results are tabulated in Table 4. 
Table 4. Stability of analyte in solution test results

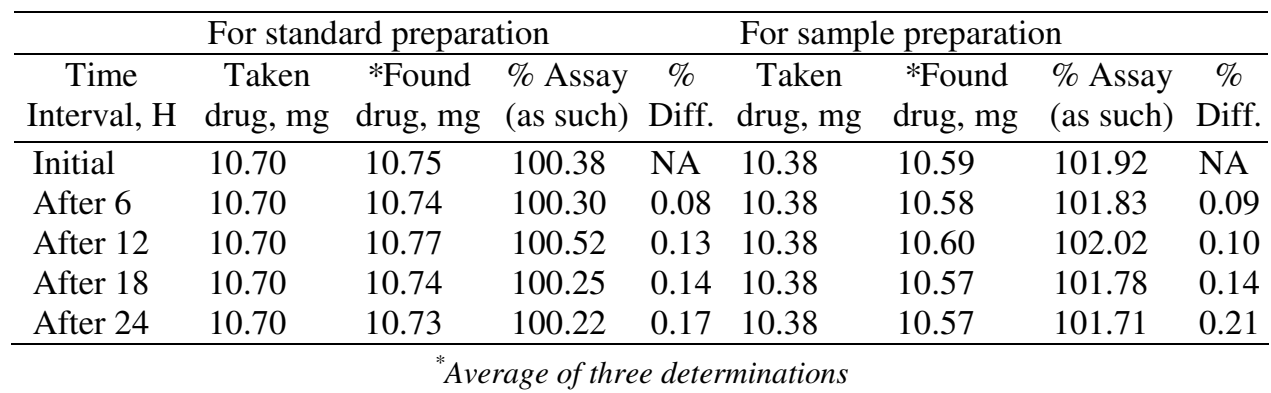

\section{Robustness}

The robustness of an analytical procedure is a measure of its capacity to remain unaffected by small but deliberate variations in procedural parameters listed in the procedure documentation and provide an indication of its suitability during normal usage. The robustness of the method was evaluated by varying two parameters independently: (1) The number of scans (64 scans \pm 16$)$ and (2) The internal standard amount (20\% variation) $(10 \pm 2.0 \mathrm{mg})$

From the results obtained as per Table 5, running the experiment using a different number of scans such as 48 or 80 rather than 64 did not affect the measurement. A variation of $20 \%$ in internal standard amount also did not appreciably change the measured amount of drug. Thereby, this method is quite robust in terms of the above-mentioned parameters.

Table 5. Results for robustness study

\begin{tabular}{ccccc}
\hline Parameter & Change & *Found drug, mg & \%Assay (as such) & \%Diff. \\
\hline Number of Scan & 48 & 10.72 & 102.08 & 0.17 \\
& 64 & 10.70 & 101.91 & NA \\
Internal Std, mg & 80 & 10.71 & 101.98 & 0.07 \\
& 8.25 & 10.76 & 101.51 & 0.39 \\
& 10.00 & 10.70 & 101.91 & NA \\
& 12.00 & 10.83 & 101.71 & 0.20 \\
\hline
\end{tabular}

*Average of three determinations

\section{Comparison with other technique (HPLC)}

Assay results obtained by qNMR were also confirmed by comparing with other in-house HPLC technique. It was found that results of HPLC method did not show any marked differences with qNMR method.

\section{Conclusion}

The qNMR method employed herein proved to be rapid as well as easy to implement. The different aspects of performance of the method, such as linearity, precision and accuracy, satisfied our requirements well. It offers an excellent choice over previously described procedures and can be used for routine quality control and stability analysis of metformin $\mathrm{HCl}$ in solid dosage forms.

Assay results obtained by qNMR were confirmed by comparing with in-house HPLC method. Furthermore, any modern NMR equipment operating at a field of $300 \mathrm{MHz}$ or more may be used, assuming that suitable processing of data is performed. qNMR has a high potential 
in analysis of pharmaceutical products due to the simplicity, reliability, simultaneous identification and quantification, and the fact that no reference compound of drug is needed.

\section{Acknowledgment}

The authors are thankful to UGC, New Delhi, INDIA, for providing the financial help for this research work under major research project (MRP).

\section{References}

1. Jungnickel J L and Forbes J W, Anal Chem., 1963, 35, 938-942.

2. Hollis D P, Anal Chem., 1963, 35, 1682-1684.

3. Liu S Y and Hu C Q, Anal Chim Acta., 2007, 602(1), 114-121.

4. Shao G, Kautz R, Peng S, Cui G and Giese RW, J Chromatogr A., 2007, 1138(1-2), 305-308.

5. Rizzo V and Pinciroli V, J Pharm Biomed Anal., 2005, 38, 851-857.

6. Zoppi A, Linares M and Longhi M, J Pharm Biomed Anal., 2005, 37, 627-630.

7. Hays P A, J Forensic Sci., 2005, 50(6), 1342-1360.

8. Hays P A and Thompson R A, Magn Reson Chem., 2009, 47(10), 819-824.

9. Sahrbacher U, Pehlke-Rimpf A, Rohr G, Eggert-Kruse W and Kalbitzer H R, $J$ Pharm Biomed Anal., 2002, 28, 827-840.

10. Wells R J, Hook J M, Al-Deen T S and Hibbert D B, J Agric Food Chem., 2002, 50, 3366-3374.

11. Xia Z, Akim L G and Argyropoulos D S, J Agric Food Chem., 2001, 49(8), 3573-3578.

12. López-Rituerto E, Cabredo S, López M, Avenoza A, Busto J H and Peregrina J M, J Agric Food Chem., 2009, 57, 2112-2118.

13. Li C Y, Xu H X, Han Q B and Wu T S, J Chromatogr A., 2009, 1216(11), 2124-2129.

14. Holzgrabe U, Diehl B W and Wawer I, J Pharm Biomed Anal., 1998, 17, 557-616.

15. Imbenotte M, Azaroual N, Cartigny B, Vermeersch G and Lhermitte M, Foren Sci Int., 2003, 133(1-2), 132-135.

16. Salem A A, Mossa H A and Barsoum B N, Spectrochim Acta Part A., 2005, 62, 466.

17. Salem A A, Mossa H A and Barsoum B N, J Pharm Biomed Anal., 2006, 41, 654-661.

18. Davidsen M B and Peters A L, Am J Med., 1997, 102, 99-110.

19. Kirpichnikov D, McFarlane S I and Sowers J R, Ann Intern Med., 2002, 137(1), 25-33.

20. James Reynolds E F, Martindale Part I, $31^{\text {st }}$ Edn., The Extra Pharmacopoeia, Royal Pharmaceutical Society of Great Britain, London, 1996.

21. DPP Research Group, N Engl J Med., 2002, 346, 393-403.

22. Onal A, Eur J Med Chem., 2009, 44, 4998-5005.

23. Al-Rimawi F, Talanta, 2009, 79(5), 1368-1371.

24. Huttunen K M, Rautio J, Leppänen J, Vepsäläinen J and Keski-Rahkonen P, J Pharm Biomed Anal., 2009, 50, 469-474.

25. Ali A R, Duraidi I I, Saket M M, Abu-Nameh E S, J AOAC Int., 2009, 92(1), 119-124.

26. Jain D, Jain S, Jain D and Amin M, J Chromatogr Sci., 2008, 46, 501-504.

27. Porta V, Schramm S G, Kano E K, Koono E E, Armando Y P, Fukuda K and Serra C H, J Pharm Biomed Anal., 2008, 46, 143-147.

28. Song J Z, Chen H F, Tian S J and Sun Z P, J Chromatogr B: Biomed Appl., 1998, 708, 277-283. 
29. Marques M A, De A, Soares S, Pinto O W, Barroso P T, Pinto D P, Ferreira-Filho M and Werneck-Barroso E, J Chromatogr B Analyt Technol Biomed Life Sci., 2007, 852(1-2), 308-316.

30. Mistri H N, Jangid A G, Shrivastav P S, J Pharm Biomed Anal., 2007, 45, 97-106.

31. Habit I H I and Kamel M S, Talanta, 2003, 60, 185-190.

32. Martinez Calatayud J, Pascual Marti M C and Campins Falco P, Analyst (Lond.), 1985, 110, 981-984.

33. Sławomira S, Valentin M, Witold C, Adam S and Robert Z, J Pharm Biomed Anal., 2007, 45, 275-281.

34. Tian X-J and Song J F, Luan, Y.Y. Wang and Q.Z. Shi, Anal Bioanal Chem., 2006, 386, 2081-2086.

35. British Pharmacopoeia, London, UK, 2009.

36. United States Pharmacopoeia 32, NF27, Rockville, Maryland, USA, 2009.

37. Malz F and Jancke H, J Pharm Biomed Anal., 2005, 38, 813-823.

38. Holzgrabe U, Diehl B and Wawer I, NMR Spectroscopy in Pharmaceutical Analysis, Elsevier Ltd., Oxford, UK, 2008, 49-50.

39. ICH Harmonized Tripartite Guidelines. Validation of Analytical Procedures: Text and Methodology Q2 (R1) 2005.

40. Maniara G, Rajamoorthi K, Srinivasan R and Stockton G W, Anal Chem., 1998, 70, 4921-4928.

41. Santoro M I, Kassab N M, Singh A K and Kedor-Hackmam E R, J Pharm Biomed Anal., 2006, 40,179-184. 


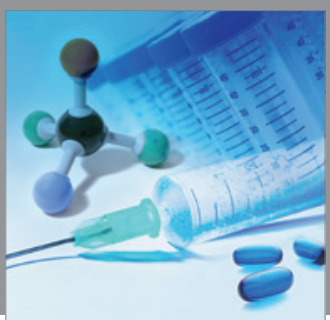

International Journal of

Medicinal Chemistry

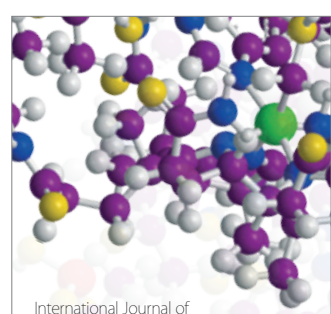

Carbohydrate Chemistry

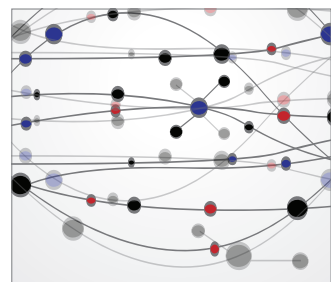

The Scientific World Journal
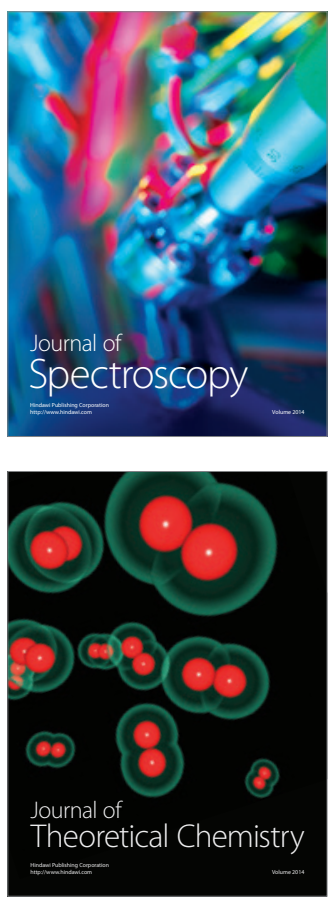
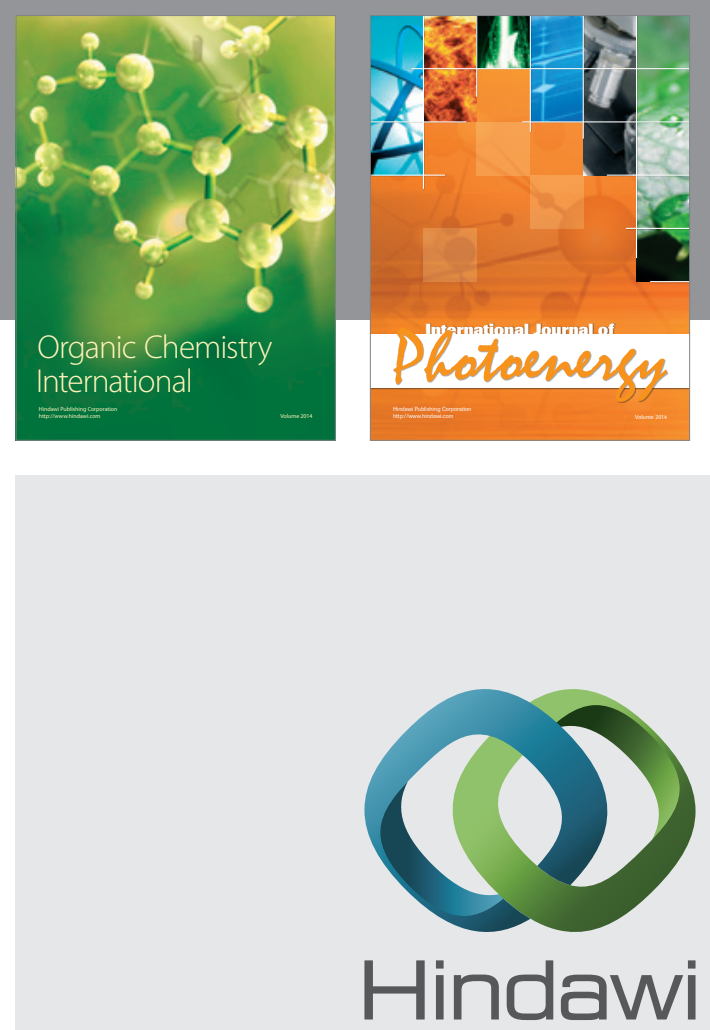

Submit your manuscripts at

http://www.hindawi.com
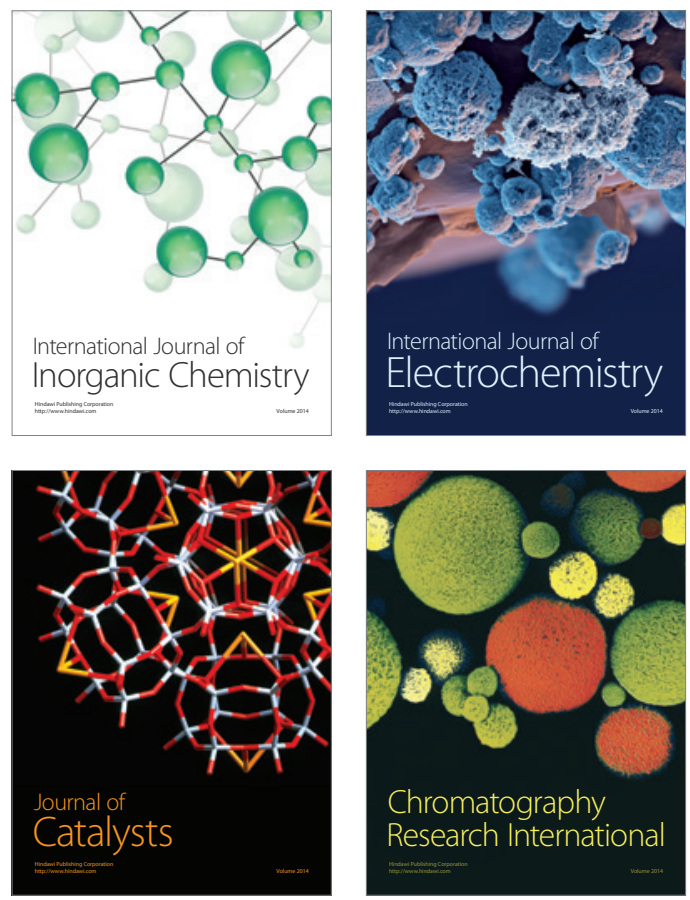
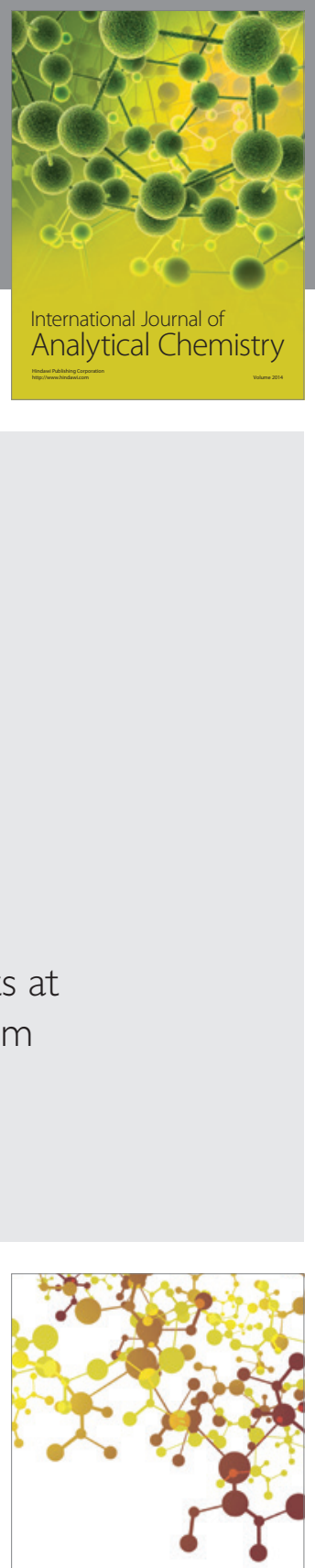

Journal of

Applied Chemistry
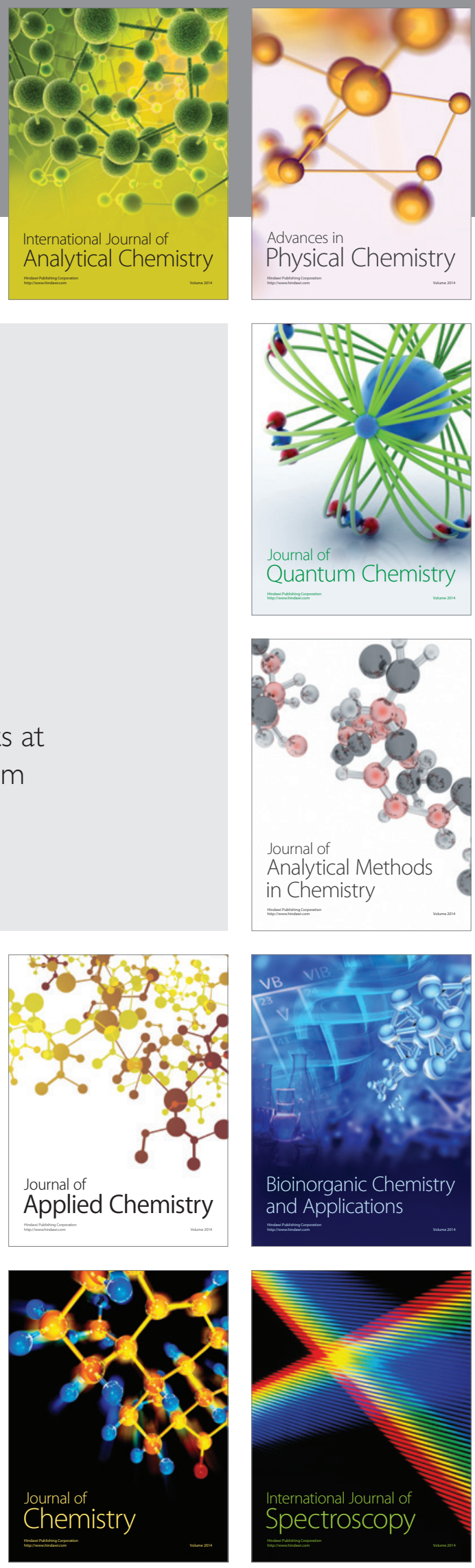